\title{
Multifaceted SlyD from Helicobacter pylori: implication in [NiFe] hydrogenase maturation
}

\author{
Tianfan Cheng $\cdot$ Hongyan Li $\cdot$ Wei Xia $\cdot$ \\ Hongzhe Sun
}

Received: 7 July 2011/Accepted: 7 October 2011/Published online: 2 November 2011

(c) The Author(s) 2011. This article is published with open access at Springerlink.com

\begin{abstract}
SlyD belongs to the FK506-binding protein (FKBP) family with both peptidylprolyl isomerase (PPIase) and chaperone activities, and is considered to be a ubiquitous cytosolic protein-folding facilitator in bacteria. It possesses a histidine- and cysteine-rich C-terminus binding to selected divalent metal ions (e.g., $\mathrm{Ni}^{2+}, \mathrm{Zn}^{2+}$ ), which is important for its involvement in the maturation processes of metalloenzymes. We have determined the solution structure of C-terminus-truncated SlyD from Helicobacter pylori $(H p S l y D \Delta C)$. $H p$ SlyD $\Delta \mathrm{C}$ folds into two well-separated, orientation-independent domains: the PPIase-active FKBP domain and the chaperone-active insert-in-flap (IF) domain. The FKBP domain consists of a four-stranded antiparallel $\beta$-sheet with an $\alpha$-helix on one side, whereas the IF domain folds into a four-stranded antiparallel $\beta$ sheet accompanied by a short $\alpha$-helix. Intact $H$. pylori SlyD binds both $\mathrm{Ni}^{2+}$ and $\mathrm{Zn}^{2+}$, with dissociation constants of 2.74 and $3.79 \mu \mathrm{M}$ respectively. Intriguingly, binding of $\mathrm{Ni}^{2+}$ instead of $\mathrm{Zn}^{2+}$ induces protein conformational changes around the active sites of the FKBP domain, implicating a regulatory role of nickel. The twin-arginine translocation (Tat) signal peptide from the small subunit of $[\mathrm{NiFe}]$ hydrogenase (HydA) binds the protein at the IF
\end{abstract}

T. Cheng and $\mathrm{H}$. Li contributed equally to the study.

Electronic supplementary material The online version of this article (doi:10.1007/s00775-011-0855-y) contains supplementary material, which is available to authorized users.

T. Cheng $\cdot$ H. Li $\cdot$ W. Xia $\cdot$ H. Sun $(\bowtie)$

Department of Chemistry,

The University of Hong Kong,

Pokfulam Road,

Hong Kong SAR,

People's Republic of China

e-mail: hsun@hku.hk domain. Nickel binding and the recognition of the Tat signal peptide by the protein suggest that SlyD participates in $[\mathrm{NiFe}]$ hydrogenase maturation processes.

Keywords Chaperone - Hydrogenase - NMR . Peptidylprolyl isomerase $\cdot$ SlyD

\begin{tabular}{|c|c|}
\hline \multicolumn{2}{|l|}{ Abbreviations } \\
\hline DTT & DL-Dithiothreitol \\
\hline EcSlyD & SlyD from Escherichia coli \\
\hline FKBP & FK506-binding protein \\
\hline HpHydA SP & $\begin{array}{l}\text { Twin-arginine translocation signal } \\
\text { peptide with the sequence taken from the } \\
{[\mathrm{NiFe}] \text { hydrogenase small subunit (pre- }} \\
\text { HydA) of Helicobacter pylori }\end{array}$ \\
\hline НрНурВ & HypB from Helicobacter pylori \\
\hline$H p$ SlyD & SlyD in Helicobacter pylori \\
\hline$H p S l y D \Delta C$ & $\begin{array}{l}\text { C-terminus-truncated SlyD from } \\
\text { Helicobacter pylori }\end{array}$ \\
\hline$H p$ SlyD $\Delta \mathrm{IF}$ & $\begin{array}{l}\text { Insert-in-flap-domain-deleted SlyD from } \\
\text { Helicobacter pylori }\end{array}$ \\
\hline$H p S l y D \Delta I F \Delta C$ & $\begin{array}{l}\text { C-terminus-truncated insert-in-flap- } \\
\text { domain-deleted SlyD from Helicobacter } \\
\text { pylori }\end{array}$ \\
\hline HsFKBP12 & Human FK506-binding protein \\
\hline HSQC & Heteronuclear single quantum coherence \\
\hline IF & Insert-in-flap \\
\hline IMAC & $\begin{array}{l}\text { Immobilized metal ion affinity } \\
\text { chromatography }\end{array}$ \\
\hline MBP & Maltose-binding protein \\
\hline MtFKBP17 & FK506-binding protein from \\
\hline & Methanothermococcus \\
\hline & thermolithotrophicus \\
\hline NOE & Nuclear Overhauser effect \\
\hline PPIase & Peptidylprolyl isomerase \\
\hline
\end{tabular}




$\begin{array}{ll}\text { RCM-La } & \begin{array}{l}\text { Reduced and carboxymethylated } \\ \alpha \text {-lactalbumin }\end{array} \\ \text { RCM-T1 } & \begin{array}{l}\text { Reduced and carboxymethylated } \\ \text { (Ser54Gly, Pro55Asn) RNase T1 }\end{array} \\ \text { RMSD } & \begin{array}{l}\text { Root mean square deviation } \\ \text { Signal-peptide-less maltose-binding } \\ \text { protein }\end{array} \\ \text { SP-less MalE } & \begin{array}{l}\text { Twin-arginine translocation } \\ \text { Tat }\end{array} \\ \text { TCEP } & \begin{array}{l}\text { Tris(2-carboxyethyl)phosphine } \\ \text { hydrochloride }\end{array} \\ \text { Tris } & \text { Tris(hydroxymethyl)aminomethane } \\ \text { TtSlyD } & \text { SlyD from Thermus thermophilus }\end{array}$

\section{Introduction}

The Gram-negative, motile, microaerophilic, flagellate bacterium Helicobacter pylori is one of the most successful pathogenic bacteria, and colonizes the human gastric mucosa and has infected more than half of the global population. H. pylori is now regarded as the leading causes of chronic gastritis, peptic and duodenal ulcers, and even gastric cancers [1]. Its survival in a high acidic environment [1] and successful pathogenesis greatly rely on its capability to produce two important enzymes, i.e., urease [2] and [NiFe] hydrogenase [3], which serve as the essential colonization factors [1]. The efficient acquisition of nickel is crucial for the enzymes to exert their proper functions. Although it is not clear how nickel enters H. pylori and is enriched under the condition of very low concentration in human serum, the NixA protein and $\mathrm{ABC}$ transporter system were proposed to be responsible for the nickel transport in $H$. pylori [1]. It has been shown that many urease- and hydrogenase-related accessory proteins play an important role in the nickel insertion into urease and hydrogenase. UreE was demonstrated to be important for the maturation of urease, but can be complemented by hydrogenase accessory proteins HypA and HypB [4], which are also critical in the maturation of hydrogenase [5]. Previous functional studies as well as an in vivo interactomics study on H. pylori revealed that both HypA and HypB together with SlyD are involved in the nickel incorporation into both urease and hydrogenase [5-7]. However, there appears to be lack of characterization of SlyD in H. pylori ( $\mathrm{HpSlyD}$ ) in spite of its counterparts being extensively studied in other species [8-11].

SlyD, as a multifaceted protein, belongs to a peptidylprolyl isomerase (PPIase) (EC 5.2.1.8) FK506-binding protein (FKBP) family, catalyzing the intrinsically slow cis-trans isomerization of peptidylprolyl bonds (Xaa-Pro) to facilitate the protein folding process $[12,13]$, but its role as a PPIase in vivo is not well understood. There are no other significant phenotype changes after the deletion of the sensitivity to lysis D gene $(\operatorname{sly} D)$ in either Escherichia coli [14] or H. pylori [15], but overexpression of SlyD can interfere with cell division and cell wall synthesis, leading to the filamentation phenotype [14]. SlyD from E. coli (EcSlyD) was found as a prominent contaminant during purification by immobilized metal ion affinity chromatography (IMAC) because of its possession of a histidine- and cysteine-rich metal-binding domain at the C-terminus [16], which is also present in $H p S l y D$. Within the N-terminal PPIase domain, there is an insertin-flap (IF) chaperone domain, compared with the sequence of an archaeal FKBP from Methanothermococcus thermolithotrophicus (MtFKBP17) [11] (Scheme 1). The histidine- and cysteine-rich C-terminus of SlyD renders it able to bind various divalent metal ions, which results in the inhibition of its PPIase activity [17], but the enhancement of nucleotide binding [18]. EcSlyD has been demonstrated to bind to various twin-arginine translocation (Tat) signal sequences both in vivo and in vitro, which prevents the export of premature proteins targeted by the Tat system [19], a system that is ubiquitously present among bacteria, including H. pylori [20], and plants [21]. This will facilitate the export of fully folded proteins from the cytoplasm across the inner/cytoplasmic membrane into the periplasm in bacteria [22]. It has been hypothesized that $H p$ SlyD might play a dual role in the maturation process of $H$. pylori [NiFe] hydrogenase through interaction with both $\mathrm{HypB}$ and the Tat signal sequence of HydA (small subunit of hydrogenase) to timely coordinate the nickel insertion with the export of holohydrogenase into the periplasm of $H$. pylori [6]. But there appears to be lack of direct evidence to support this hypothesis.

To understand the $\mathrm{Ni}^{2+}$ flow in $H$. pylori, we have systematically studied structurally and/or functionally a series of metalloproteins from $H$. pylori, including $\mathrm{Ni}^{2+}$ storage proteins, e.g., Hpn [23-25] and Hpnl [26], and metallochaperone proteins, e.g., HspA [27] and HypA/ HypB [28]. In the work reported here, we overexpressed and purified $H p S l y D$ and its variants. The solution structure of $H p$ SlyD (1-151, C-terminus-truncated $H p$ SlyD, $H p \operatorname{SlyD} \Delta \mathrm{C}$ ) showed an overall topology similar to that of its homologues with two independent domains (FKBP and IF). We also performed biochemical and physical studies to explore the metal binding properties of HpSlyD and its potential roles in the maturation of $[\mathrm{NiFe}]$ hydrogenase of H. pylori. 


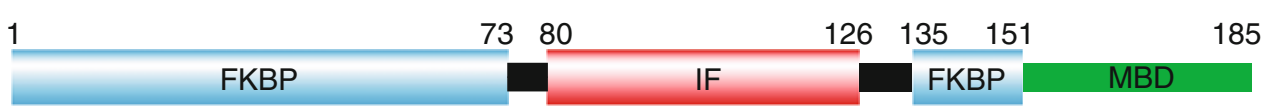

Scheme 1 Domain organization of SlyD in Helicobacter pylori (HpSlyD). Cyan boxes FK506-binding protein (FKBP) domains, red box insertin-flap $(I F)$ domain, green line metal-binding domain $(M B D)$, black lines linkers

\section{Materials and methods}

Molecular cloning

PCR amplification was performed using Phusion ${ }^{\circledR}$ highfidelity DNA polymerase (Finnzymes). All restriction endonucleases were purchased from New England BioLabs. E. coli XL-1 Blue (Stratagene) was used for cloning. H. pylori slyD and all its variant genes were inserted into the plasmid pET-32a $(+)$ (Novagen) for expression. All primers and plasmids used and constructed in this study are listed in Table S1.

H. pylori slyD gene was amplified from $H$. pylori 26695 genomic DNA using the primer pair HpSlyD-for/HpSlyDrev. $s l y D \Delta \mathrm{C}$ gene was amplified using HpSlyD-for/ HpSlyD $\Delta$ C-rev. To generate IF-domain-deleted HpSlyD ( $H p S l y D \Delta I F)$, the IF domain of $H p S l y D$ was replaced by the hFKBP12 loop (ATGHPGIIPPHAT) [29] and the primer pairs HpSlyD-for/ $\Delta \mathrm{IF}-1$ and $\Delta \mathrm{IF}-2 / \mathrm{HpSlyD}$-rev were used for overlap PCR.

To express and purify the Tat signal peptide with the sequence taken from the [NiFe] hydrogenase small subunit (pre-HydA) of $H$. pylori (HpHydA SP), a signal-peptideless maltose-binding protein (MBP) (SP-less MalE) expression vector was constructed in a manner similar to that in a previous description [30] by amplifying malE $\Delta \mathrm{SP}$ from pMAL-p2x (New England BioLabs) using the primer pair MalE-SPless/MalE-Xa and inserted into pET-32a(+), generating pETMalE. pETMalE was then digested by EcoRI and XhoI, blunted by T4 DNA polymerase (New England BioLabs), and circulated again with T4 DNA ligase (Invitrogen), generating pETMalEHis, which encodes the MalE protein with a factor Xa cleavage site, a flexible extension, and a hexahistidine tag at the C-terminus (ФMalE::H6). The coding sequence of HpHydA SP was PCR-amplified from $H$. pylori 26695 genomic DNA using HydA-SP-up/HydA-SP-down, digested by EcoRI and $X h o I$, and cloned into pETMalEHis, generating pETMalEHydASP (product ФMalE::HydASP-H6).

Protein expression and purification

E. coli strain KM1603 [BL21(DE3) $\Delta$ slyD::kan (a gift from A.R. Davidson, University of Toronto)] was used for expressing all proteins in this study to exclude the contamination of SlyD from E. coli. The proteins were overexpressed in $1 \mathrm{~L} \mathrm{LB}$ medium at $30{ }^{\circ} \mathrm{C}$ for $3-5 \mathrm{~h}$ after the addition of $0.2 \mathrm{mM}$ isopropyl $\beta$-D-1-thiogalactopyranoside. For isotopically $\left({ }^{15} \mathrm{~N} /{ }^{13} \mathrm{C}\right)$ labeled proteins, proteins were overexpressed in $1 \mathrm{~L}$ M9 minimal medium, supplemented with either $1 \mathrm{~g}{ }^{15} \mathrm{NH}_{4} \mathrm{Cl}$ or and $4 \mathrm{~g} \mathrm{D}$-[U- $\left.{ }^{13} \mathrm{C}_{6}\right]$ glucose (Cambridge Isotope) at $25{ }^{\circ} \mathrm{C}$ for $22 \mathrm{~h}$.

$\mathrm{HpSlyD}$ and its variants were purified on an ÄKTAFPLC $^{\text {TM }}$ system (GE Healthcare). Briefly, cultured cells were lysed in a lysis buffer [20 $\mathrm{mM}$ tris(hydroxymethyl)aminomethane (Tris)/ $\mathrm{HCl}, \mathrm{pH} 8.0,1 \mathrm{mM}$ phenylmethanesulfonyl fluoride, $1 \mathrm{mM}$ DL-dithiothreitol (DTT), and $1 \mathrm{mM}$ EDTA] and loaded onto a HiPrep DEAE FF $16 / 10$ column. Proteins were eluted by a gradient of $0-500 \mathrm{mM} \mathrm{NaCl}$. Targeted protein-containing fractions were pooled together, concentrated, and loaded onto a HiLoad 16/10 Superdex 75 pg column preequilibrated with $20 \mathrm{mM}$ Tris/HCl buffer, $\mathrm{pH}$ 7.6, $1 \mathrm{mM}$ DTT, $1 \mathrm{mM}$ EDTA, and $150 \mathrm{mM} \mathrm{NaCl}$. Eluted proteins were further purified using a RESOURCE Q or Mono Q column with a gradient of $0-500 \mathrm{mM} \mathrm{NaCl}$ in $20 \mathrm{mM}$ Tris/HCl, $\mathrm{pH} 7.6$, $1 \mathrm{mM}$ DTT. Prior to each experiment, $H p S l y \mathrm{D}$ was treated with EDTA and tris(2-carboxyethyl)phosphine hydrochloride (TCEP) overnight and desalted into the buffer for the experiment. The purity of the proteins was more than $90 \%$ as judged by sodium dodecyl sulfate polyacrylamide gel electrophoresis and the identities of the proteins were verified by matrix-assisted laser desorption/ionization timeof-flight tandem mass spectrometry analyses.

ФMalE::H6 and ФMalE::HydASP-H6 were purified by IMAC using a HisTrap HP column followed by size-exclusion chromatography. Protein concentration was determined by a bicinchoninic acid protein assay kit (Novagen) or UVvis spectroscopy according to the predicated absorption coefficient $\left(\varepsilon_{280}\right)$ using ProtParam (http://expasy.org/tools/ protparam.html) (only for apoprotein samples) or the previously reported values $[8,31]$. The molar absorption coefficients $\left(\varepsilon_{278}\right)$ for reduced and carboxymethylated (Ser54Gly, Pro55Asn) RNase T1 (RCM-T1) and reduced and carboxymethylated $\alpha$-lactalbumin (RCM-La) are 21,060 and $28,340 \mathrm{M}^{-1} \mathrm{~cm}^{-1}$, respectively, and $\varepsilon_{280}$ for $H p$ SlyD (reduced) and $H p S l y D \Delta C$ is $12,950 \mathrm{M}^{-1} \mathrm{~cm}^{-1}$ and for $H p$ SlyD $\Delta \mathrm{IF}$ (reduced) and $\mathrm{C}$-terminus-truncated $H p \operatorname{SlyD} \Delta \mathrm{IF}(H p \operatorname{SlyD} \Delta \mathrm{IF} \Delta \mathrm{C})$ is $8,480 \mathrm{M}^{-1} \mathrm{~cm}^{-1}$.

\section{Equilibrium dialysis}

The dissociation constants of HpSlyD-metal complexes were determined by equilibrium dialysis using a $1-\mathrm{kDa}$ 
cutoff mini dialysis kit (GE Healthcare). Known amounts of the protein $(200 \mu \mathrm{L}, 20 \mu \mathrm{M})$ were loaded into the dialysis tubes and dialyzed against $30 \mathrm{~mL}$ dialysis buffer $(20 \mathrm{mM}$ Tris/ $\mathrm{HCl}$ and $150 \mathrm{mM} \mathrm{NaCl}, \mathrm{pH} 7.6,200 \mu \mathrm{M}$ TCEP) containing different concentrations of $\mathrm{Ni}^{2+}$ (as $\mathrm{NiSO}_{4}$, from 0.5 to $80 \mu \mathrm{M}$ ) or $\mathrm{Zn}^{2+}$ (as $\mathrm{ZnSO}_{4}$, from 0.5 to $80 \mu \mathrm{M}$ ) for overnight incubation at $15^{\circ} \mathrm{C}$. The metal concentrations inside and outside the dialysis tubes were determined by inductively coupled plasma mass spectrometry (Agilent 7500 spectrometer). The maximal binding capacity $\left(B_{\max }\right)$ and dissociation constants $\left(K_{\mathrm{d}}\right)$ were obtained and averaged from three independent experiments using a one-site binding equation: $Y=B_{\max } X /\left(K_{\mathrm{d}}+X\right)$, where $X$ is the concentration of free metal ions and $Y$ is the molar ratio of bound metal ions to protein.

UV-vis spectroscopy

All UV-vis spectra were collected with a Varian Cary 50 spectrophotometer using a $1-\mathrm{cm}$ quartz cuvette at room temperature. Apo- $H p$ SlyD samples $(30 \mu \mathrm{M})$ were freshly prepared in $10 \mathrm{mM} N$-(2-hydroxyethyl)piperazine- $N^{\prime}$-ethanesulfonic acid/ $\mathrm{NaOH}$ buffer containing $50 \mathrm{mM} \mathrm{NaCl}, \mathrm{pH}$ 7.4, and prior to titration, an aliquot of a concentrated solution of TCEP was added to give 10 molar equiv of the protein. The spectrum of apo- $H p$ SlyD containing TCEP was recorded after equilibration for $30 \mathrm{~min}$. Aliquots of stock solution of $\mathrm{Ni}^{2+}$ (as $\mathrm{NiSO}_{4}$ ) were then titrated into the sample, and UV-vis absorption spectra were recorded in the range from 230 to $600 \mathrm{~nm}$. Binding of $\mathrm{Ni}^{2+}$ was monitored by the increase in absorbance at 246, 278, 333, and $420 \mathrm{~nm}$.

\section{NMR spectroscopy}

All spectra were acquired at $25{ }^{\circ} \mathrm{C}$ with a Bruker Avance 600 spectrometer operated at a frequency of $600.13 \mathrm{MHz}$ for ${ }^{1} \mathrm{H}$ and equipped with a triple resonance (TCI) CryoProbe. Spectra for assignment of $H p \operatorname{SlyD} \Delta \mathrm{C}$ were recorded in an about $1.3 \mathrm{mM}{ }^{15} \mathrm{~N} /{ }^{13} \mathrm{C}$ doubly labeled sample in the NMR buffer ( $20 \mathrm{mM}$ [bis(2-hydroxyethyl)aminotris(hydroxymethyl)methane/ $\mathrm{HCl}$ buffer and $100 \mathrm{mM}$ $\mathrm{NaCl}, \mathrm{pH} 6.8$, containing $10 \%$ (v/v) $\mathrm{D}_{2} \mathrm{O}, 0.02 \% \mathrm{NaN}_{3}$ ). All NMR data were processed with either NMRPIPE [32] or XWINNMR and were analyzed by SPARKY [33]. Distance restraints were obtained on the basis of two 3D ${ }^{15} \mathrm{~N} /{ }^{13} \mathrm{C}$-edited nuclear Overhauser effect (NOE) spectroscopy experiments. Hydrogen-bond amide protons were identified by acquiring a series of $2 \mathrm{D}\left[{ }^{1} \mathrm{H}-{ }^{15} \mathrm{~N}\right]$ heteronuclear single quantum coherence (HSQC) spectra at a range of temperatures $\left(10-35{ }^{\circ} \mathrm{C}\right)$. Backbone dihedral angles were derived on the basis of the chemical shifts of $\mathrm{C}_{\alpha}, \mathrm{C}_{\beta}$, and $\mathrm{C}^{\prime}$ from TALOS [34]. $T_{1}, T_{2}$, and $\left\{{ }^{1} \mathrm{H}\right\}-{ }^{15} \mathrm{~N}$ NOE measurements were performed by collecting a time series of $\left[{ }^{1} \mathrm{H}-{ }^{15} \mathrm{~N}\right] \mathrm{HSQC}$ spectra with sensitivity enhancement and analyzed by NMRPIPE.

For the $\mathrm{Ni}^{2+}$ titration experiment, a $2 \mathrm{D}\left[{ }^{1} \mathrm{H}_{-}{ }^{15} \mathrm{~N}\right] \mathrm{HSQC}$ spectrum of $0.3 \mathrm{mM}{ }^{15} \mathrm{~N}$-labeled full-length $H p$ SlyD was recorded and compared with the spectrum of $H p \operatorname{SlyD} \Delta \mathrm{C}$, and most of the backbone amides of full-length HpSlyD were therefore assigned. A series of $\left[{ }^{1} \mathrm{H}-{ }^{15} \mathrm{~N}\right]$ HSQC spectra were acquired before and after addition of $40 \mathrm{mM}$ $\mathrm{NiSO}_{4}$ in NMR buffer at molar ratios of $\mathrm{Ni}^{2+}$ to the protein of $0.3,0.6,1.0,1.5$, and 2.0 , respectively. Solutions of $0.1-0.3 \mathrm{mM}{ }^{15} \mathrm{~N}$-labeled $H p \operatorname{SlyD} \Delta \mathrm{C}$ were used for titrations of FK506, rapamycin, and permanently unfolded protein and peptide substrates, which were added stepwise at molar ratios of substrates to the protein of $0.5,1$, and 1.25. The mean weighted variations of ${ }^{15} \mathrm{~N}$ and ${ }^{1} \mathrm{H}$ chemical shifts upon titrations of $\mathrm{Ni}^{2+}$ and substrates were calculated as reported previously [35] using the following equation:

$\Delta \delta_{\mathrm{av}(\mathrm{HN})}=\sqrt{\frac{\left(\Delta \delta_{1_{\mathrm{H}}}\right)^{2}+\left(0.2 \Delta \delta_{15_{\mathrm{N}}}\right)^{2}}{2}}$.

Structure calculation

The solution structure of $H p \operatorname{SlyD} \Delta \mathrm{C}$ was calculated by torsion angle dynamics using CYANA 2.1 [36] on the basis of NOE-derived distance constraints, hydrogen-bond constraints, and TALOS angle constraints. A set of 200 structures was initiated and a standard protocol of an automated NOE assignment approach was applied. A set of 50 structures with the lowest target functions and no NOE violation larger than $4.0 \AA$ and torsion angle violation larger than $5^{\circ}$ was chosen and subjected to further energy minimization using AMBER 7 [37]. The final 20 energyminimized and best-converged structures were selected to represent the ensemble, and the quality of the structures was assessed by PROCHECK-NMR [38] and analyzed by MOLMOL [39]. The structure was displayed by MOLMOL and PyMOL [40].

\section{Results}

Secondary structure of $\mathrm{HpSlyD}$

$H p S l y \mathrm{D}$ and its C-terminus-truncated variants $(H p S l y D \Delta C)$ were successfully expressed and purified to apparent homogeneity (Fig. S1). The purified HpSlyD was subjected to gel filtration chromatography on a Superdex 10/300 GL column (GE Healthcare) and was calibrated as an apparent molecular mass of approximately $33 \mathrm{kDa}$ in the presence of TCEP using an LMW gel filtration 


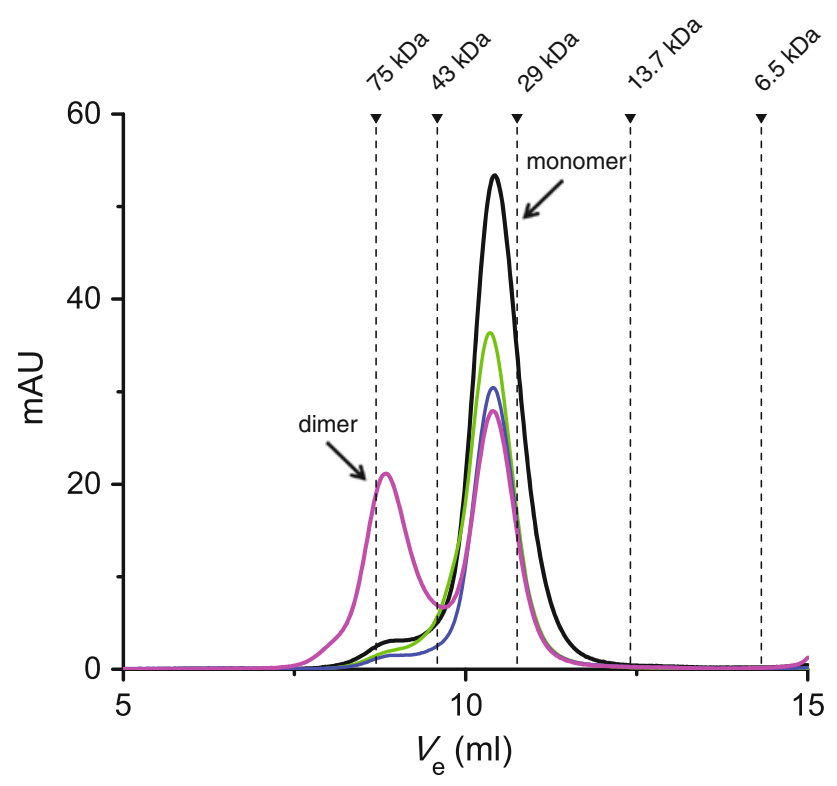

Fig. 1 Gel filtration chromatography profiles of $10 \mu \mathrm{M} H p$ SlyD in the absence of metal ions (black) and in the presence of 5 molar equiv of $\mathrm{Ni}^{2+}$ (green) and $\mathrm{Zn}^{2+}$ (blue) without incubation and $\mathrm{Zn}^{2+}$ with overnight incubation (magenta). The experiments were performed using a Superdex 10/300 GL column (GE Healthcare) with $20 \mathrm{mM}$ tris(hydroxymethyl)aminomethane/ $\mathrm{HCl}$ buffer, $150 \mathrm{mM} \mathrm{NaCl}, \mathrm{pH}$ 7.6, at $4{ }^{\circ} \mathrm{C}$. Similar profiles were also observed when 2 molar equiv of metal ions was added. Apo-HpSlyD was calibrated as an apparent molecular mass of about $33 \mathrm{kDa}$, larger than the calculated value, i.e., $20 \mathrm{kDa}$. The dimer was calibrated as about $65 \mathrm{kDa}$

calibration kit (GE Healthcare) (Fig. 1). A larger molecular mass observed by both size-exclusion chromatography and sodium dodecyl sulfate polyacrylamide gel electrophoresis (approximately $25 \mathrm{kDa}$, Fig. S1) in comparison with the calculated one (approximately $20 \mathrm{kDa}$ ) was also seen previously for SlyD from other species [18, 41], probably attributable to the elongated shape of the protein. We therefore subjected the purified $H p S l y D$ to electrospray ionization mass spectrometry and obtained a molecular mass of 19,995.84 Da (Fig. S2), confirming that HpSlyD exists as a monomer in solution under the conditions used. Deconvolution of the circular dichroism spectrum (190-260 nm) of HpSlyD (Fig. S3) gave rise to secondary structure contents of about $7 \% \alpha$-helix, $43 \% \beta$-sheet, $17 \%$ turn, and $33 \%$ random coil. Addition of selected metal ions (i.e., $\mathrm{Ni}^{2+}$ and $\mathrm{Zn}^{2+}$ ) to a solution of $\mathrm{HpSlyD}$ did not change the examined circular dichroism spectrum (190-260 nm) (data not shown), indicating there were no significant effects on the secondary structure of the protein.

Solution structure determination of $H p \operatorname{SlyD} \Delta \mathrm{C}$

The $\left[{ }^{1} \mathrm{H}_{-}-{ }^{15} \mathrm{~N}\right]$ HSQC spectra of both full-length $H p$ SlyD (1-185) and $H p \operatorname{SlyD} \Delta \mathrm{C}(1-151)$ were compared and nearly all the resonances from $H p \operatorname{SlyD} \Delta \mathrm{C}$ can be overlaid with those from the full-length protein, indicating that the C-terminal residues have little effect on the structure of the protein. Backbone resonances of ${ }^{13} \mathrm{C} /{ }^{15} \mathrm{~N}$ doubly labeled $H p S l y D \Delta C$ were assigned using standard triple-resonance experiments such as $\mathrm{HNCACB}, \mathrm{CBCA}(\mathrm{CO}) \mathrm{NH}, \mathrm{HNCO}$, and $\mathrm{HNCA}$, whereas $\mathrm{HCCH}$-total correlation spectroscopy, $\mathrm{HCCH}-$ correlation spectroscopy, and $\mathrm{HBHA}(\mathrm{CO}) \mathrm{NH}$ were used for the aliphatic side chain assignment. The solution structure of $H p \operatorname{SlyD} \Delta \mathrm{C}$ was determined using CYANA 2.1 on the basis of 2,525 NOE distance constraints derived from ${ }^{15} \mathrm{~N} /{ }^{13} \mathrm{C}$-edited NOE spectroscopy and 164 TALOS angle constraints derived from chemical shifts of $\mathrm{C}_{\alpha}, \mathrm{C}_{\beta}$, and $\mathrm{C}^{\prime}$ and 68 hydrogen-bond constraints derived from both experimental data and NOE patterns. Structural statistics are summarized in Table 1 . An ensemble of the 20 best converged energy-minimized structures exhibits high convergence within the FKBP domain (Fig. 2a) and the IF domain (Fig. 2b). The structure close to the average one was chosen to represent $H p S l y D \Delta C$ and is shown in a ribbon model (Fig. 2c).

Structural description and comparison with other homologues

As shown in Fig. 2c, $H p \operatorname{SlyD} \Delta \mathrm{C}$ folds into two separated globular domains, i.e., the FKBP domain and the IF domain, linked by a deep cleft. The FKBP domain is formed by two polypeptide segments consisting of $73 \mathrm{~N}$-terminal redidues (1-73) and 17 C-terminal residues (135-151), and the IF domain comprises residues $80-126$. The connecting segments span residues 74-79 and 127-134, forming a pair of antiparallel strands and hinging the bending motion of the domains. These segments are relatively less well defined owing to the limited numbers of NOEs assigned.

The relative orientation of the two domains is poorly defined and no unambiguous contacts (NOEs) were identified between the two domains. When the orientation of the two domains was fixed by superimposing the structures over the well-defined residues of entire molecules, a very large root mean square deviation (RMSD) (larger than $5 \AA$ ) was noted. In comparison, small RMSDs were obtained when each domain was overlaid over well-defined residues separately (Table 1). The average overall rotational correlation time for the two domains was estimated on the basis of the backbone dynamic data (Fig. S4) to be 13.1 and 15.2 ns for the IF and FKBP domains, respectively, in line with the two-domain structure. The poorly defined orientation between the FKBP and IF domains was also seen for other SlyDs, e.g., EcSlyD, as well as the structural and functional homologue MtFKBP17.

The FKBP domain consists of a canonical four-stranded antiparallel $\beta$-sheet accompanied by $\alpha 1$ on one side (Fig. 2c), with a topology of $\beta 4-\beta 5-\alpha 1-\beta 2-\beta 3$, which 
Table 1 Summary of structural statistics

\begin{tabular}{|c|c|}
\hline Total number of NOE cross-peaks & 4,546 \\
\hline NOE-derived distance restraints & 2,525 \\
\hline Short range $|i-j| \leq 1$ & 1,373 \\
\hline Medium range $1<|i-j|<5$ & 288 \\
\hline Long range $|i-j| \geq 5$ & 864 \\
\hline H-bond constrains & 68 \\
\hline$\phi / \psi$ dihedral angle constraints (TALOS) & 164 \\
\hline Residual NOE target function $\left(\AA^{2}\right)$ & 1.61 \\
\hline \multicolumn{2}{|l|}{ Deviations from the experimental restraints } \\
\hline RMS distance restraint violation $(\AA)$ & $0.0082 \pm 0.0007$ \\
\hline $\begin{array}{l}\text { Number of distance restraint violations } \\
\text { greater than } 0.4 \AA\end{array}$ & 0 \\
\hline Maximum distance restraint violations $(\AA)$ & 0.37 \\
\hline RMS dihedral angle restraint violations $\left(^{\circ}\right)$ & $0.12 \pm 0.06$ \\
\hline $\begin{array}{l}\text { Number of dihedral angle restraint } \\
\text { violations greater than } 3^{\circ}\end{array}$ & 1 \\
\hline AMBER energy $(\mathrm{kJ} / \mathrm{mol})$ & $-23,804.34 \pm 88.62$ \\
\hline \multicolumn{2}{|l|}{ Pairwise atomic RMSD from the mean $(\AA)$} \\
\hline \multicolumn{2}{|l|}{ PPIase domain ${ }^{\mathrm{a}}$} \\
\hline Backbone heavy atoms & $0.46 \pm 0.09$ \\
\hline All heavy atoms & $1.16 \pm 0.16$ \\
\hline \multicolumn{2}{|l|}{ IF domain ${ }^{\mathrm{b}}$} \\
\hline Backbone heavy atoms & $0.70 \pm 0.19$ \\
\hline All heavy atoms & $1.41 \pm 0.25$ \\
\hline \multicolumn{2}{|l|}{ Ramachandran analysis $(\%)$} \\
\hline Most favored region & 83.0 \\
\hline Additionally allowed region & 17.0 \\
\hline Generously allowed region & 0.0 \\
\hline Disallowed region & 0.0 \\
\hline Overall $G$ factor & $-0.25 \pm 0.03$ \\
\hline H-bond energy $(\mathrm{kJ} / \mathrm{mol})$ & 2.93 \\
\hline
\end{tabular}

$N O E$ nuclear Overhauser effect, $R M S$ root mean square, $R M S D$ root mean square deviation, PPIase peptidylprolyl isomerase, IF insert-inflap

${ }^{a}$ Residues 12-21, 27-30, 37-40, 48-54, 63-67, and 135-145

b Residues 81-89, 99-104, 108-118, and 121-126

Fig. 2 The 20 lowest-energy solution structures of C-terminus-truncated $\mathrm{HpSlyD}$ ( $H p \mathrm{SlyD} \Delta \mathrm{C})$ superimposed over the backbone coordinates of well-defined regions for the FKBP domain (a) and the IF domain (b) and ribbon diagram of the mean structure of $H p S l y D \Delta C$ with the helices shown in orange and $\beta$-sheets shown in pale green $(\mathbf{c})$

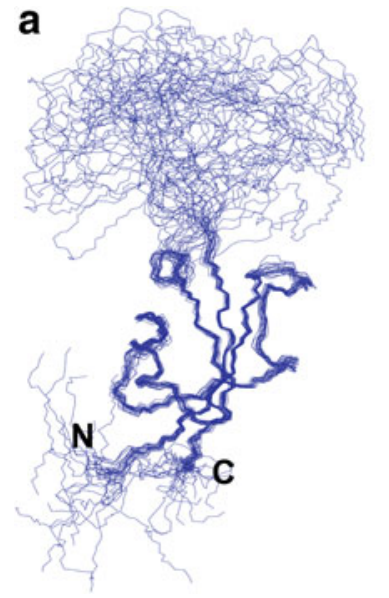

closely resembles the structures of the FKBP domains of other FKBPs. The secondary structure elements were named according to the convention used for other FKBPs. $\alpha 1$ is amphipathic with apolar residues pointing to the $\beta$-sheet to make hydrophobic contacts and polar residues that are solvent-exposed. Similar to the structures of MtFKBP17 and other SlyDs, HpSlyD $\Delta \mathrm{C}$ lacks an N-terminal $\beta 1$, as observed in human FKBP (HsFKBP12) [42]. $\beta 5$ of $H p S l y D \Delta C$ is split into two halves separated by a five-residue bulge loop as in EcSlyD and HsFKBP12, but different from MtFKBP17 and SlyD from Thermus thermophilus (TtSlyD), whereas a unique helix, $\alpha 2$, is found to separate strand $\beta 5$ to $\beta 5 \mathrm{a}$ and $\beta 5 \mathrm{~b}$ in MtFKBP17 and no splitting of $\beta 5$ occurs in TtSlyD. An additional helix, $\alpha 4$, found in EcSlyD and TtSlyD was not observed in HpSlyD, probably owing to the truncation point selected in the present study. $\alpha 4$ of EcSlyD is formed by residues 144-149, corresponding to residues 148-153 of HpSlyD. Nevertheless, our bioinformatic studies demonstrated indeed the presence of $\alpha 4$, suggesting that $\alpha 4$ is likely to be the common feature for the structures of the SlyD family. This is distinct from other FKBPs and it may therefore serve an important biological function (vide infra). A small helix at the end of $\beta 2$ is formed by residues 69-73 in $H p \operatorname{SlyD} \Delta \mathrm{C}$, which is also observed in the two crystal structures of the non-substrate-peptide-bound form of TtSlyD. However, this helix was not observed in the structures of EcSlyD, MtFKBP17, and substrate-peptidebound TtSlyD; instead, a reversed turn was found in these structures. The pairwise structural comparison of $H p S l y D \Delta C$ with other homologues, e.g. HsFKBP12 (1FKF) [42], EcSlyD (2K8I) [9], and TtSlyD (3CGM) [8], was made with the aid of DaliLite [43], and the aligned structures are shown representatively in Fig. 3. The FKBP domain of $H p S l y D \Delta C$ can be superimposed well with that of HsFKBP12, EcSlyD, and TtSlyD, with RMSDs of 2.5, 3.4 , and $3.2 \AA$ over the $\mathrm{C}_{\alpha}$ atoms of 81,88 , and 80 , respectively, identified by DaliLite.

b

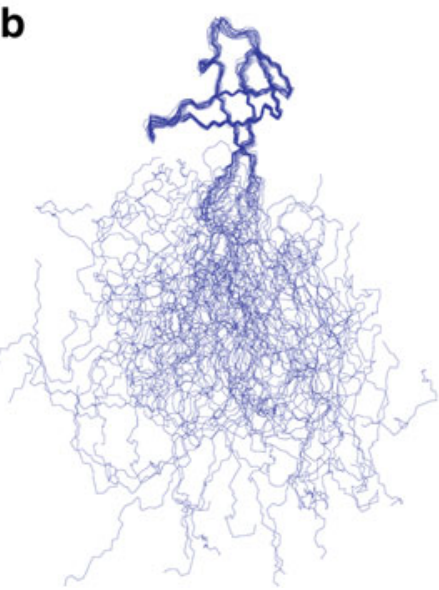

C

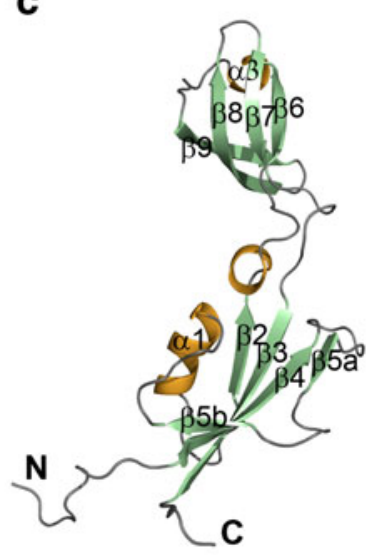


Fig. 3 Superimposition of the FKBP domain of $H p S l y D \Delta C$ FKBP (HsFKBP12) (orange), b SlyD from Thermus thermophilus (TtSlyD) (pale green), and c SlyD from Escherichia coli (EcSlyD) (pink) was shown. The structures were aligned over $\mathrm{C}_{\alpha}$ residues identified using DaliLite [43] and the images were generated using PyMOL [40] (sky blue) with that of a human

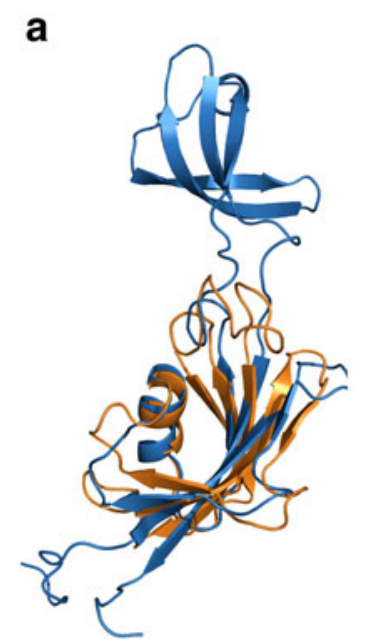

The IF domain displays a topology of $\beta 6-\alpha 3-\beta 9-\beta 8-\beta 7$ and folds into a four-stranded antiparallel $\beta$-sheet and a short helix, $\alpha 3$, which connects $\beta 6$ and a partially flexible loop leading to $\beta 9$ (Fig. 2c). The side chains of Phe-89 and Arg-86 from $\alpha 1$ interact with the side chains of Val-84, Val-100, Ile114, Phe-117, Val-122, and Val-124 from the $\beta$-sheet and Ile-92 and Leu-94 from the flexible loop, forming a hydrophobic core to stabilize the structure. Extremely high similarity was noted among the structures of IF domains of SlyD or its homologues from different species, and RMSDs of 1.8 and $2.2 \AA$ were found when the structural alignment was made for the IF domain of $H p S l y D$ and EcSlyD or TtSlyD via DaliLite. Importantly, a large proportion of apolar residues $(50 \%)$ is noted for this domain, which gives rise to large exposed hydrophobic surfaces. Moreover, the backbone dynamic data (Fig. S4) demonstrated that the IF domain generally has a a higher degree of mobility in comparison with the FKBP domain, in agreement with its counterpart EcSlyD. The characteristics of high flexibility and large exposed hydrophobic surfaces may allow it to rapidly adopt different conformations, resulting in facilitating association with or dissociation from unfolded or partially folded proteins or substrates.

\section{Metal binding properties}

The full-length $H p S l y D$ was used to study its interaction with metal ions such as $\mathrm{Ni}^{2+}$ and $\mathrm{Zn}^{2+}$. When $\mathrm{Ni}^{2+}$ was titrated in a step of 0.25 molar equiv into $30 \mu \mathrm{M} H p S l y D, p H ~ 7.4$, in the presence of $300 \mu \mathrm{M}$ TCEP, four new peaks centered at approximately 246, 278, 333, and $420 \mathrm{~nm}$ appeared gradually in the difference electronic absorption spectra, indicative of the binding of $\mathrm{Ni}^{2+}$ to the protein (Fig. 4a). According to a previous study on nickel binding to small molecules [44], the absorption bands at 278 and $333 \mathrm{~nm}$ are due to $\sigma(\mathrm{S})(\mathrm{Cys}) \rightarrow \mathrm{Ni}(\mathrm{II})$ and $\pi(\mathrm{S})(\mathrm{Cys}) \rightarrow \mathrm{Ni}(\mathrm{II})$ ligand-tometal charge transfer transitions, whereas the one at $246 \mathrm{~nm}$
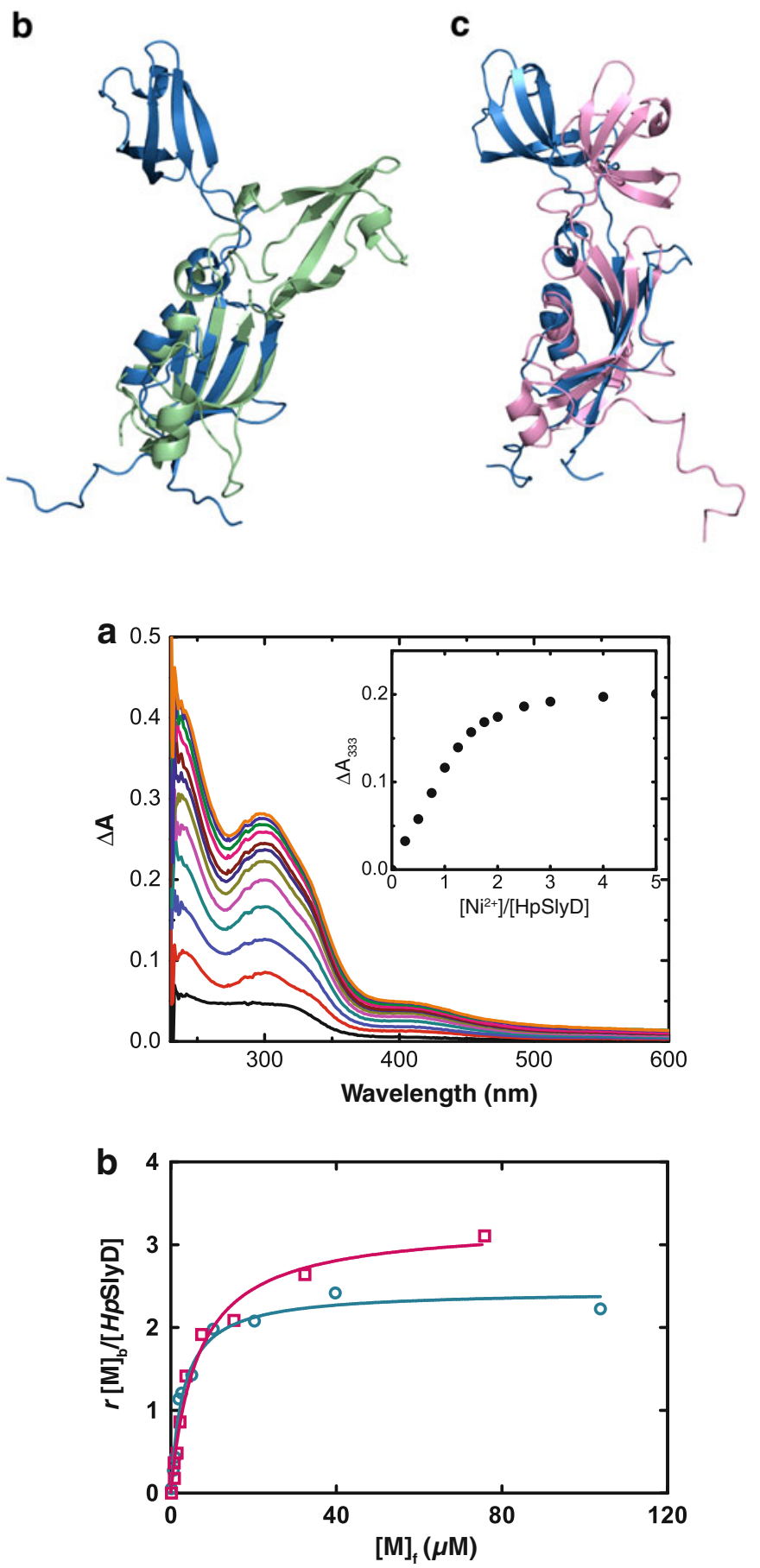

Fig. 4 a UV difference spectra of $30 \mu \mathrm{M} H p$ SlyD with addition of $0.25-5$ molar equiv of $\mathrm{Ni}^{2+}$. The titration curve plotted with $\Delta A_{333}$ is shown in the inset. b Metal binding affinity of HpSlyD determined by equilibrium dialysis: $\mathrm{Ni}^{2+}$ (circles) and $\mathrm{Zn}^{2+}$ (squares)

is due to a $\sigma(\mathrm{N})(\mathrm{His}) \rightarrow \mathrm{Ni}(\mathrm{II})$ ligand-to-metal charge transfer transition. The $420-\mathrm{nm}$ band may be due to a $d-d$ transition of $\mathrm{Ni}^{2+}$ [45], as for other metal-binding proteins [24, 27, 28, 46]. These bands increased in intensity further upon addition of metal ions and the intensity leveled off at a molar ratio of $\mathrm{Ni}^{2+}$ to $\mathrm{HpSlyD}$ of approximately 2 
(Fig. 4a inset). The binding of $\mathrm{Ni}^{2+}$ and $\mathrm{Zn}^{2+}$ was further investigated by equilibrium dialysis (Fig. $4 b$ ), which revealed stoichiometry of $2.4 \pm 0.1$ nickel ions per protein and $3.3 \pm 0.2$ zinc ions per protein with dissociation constants $\left(K_{\mathrm{d}}\right)$ of $2.74 \pm 0.26$ and $3.79 \pm 0.92 \mu \mathrm{M}$ for $\mathrm{Ni}^{2+}$ and $\mathrm{Zn}^{2+}$, respectively. No oligomerization of the protein was observed upon addition of 2 or even 5 molar equiv of $\mathrm{Ni}^{2+}$. In contrast, dimerization was found upon incubation of the protein with 2 and 5 molar equiv of $\mathrm{Zn}^{2+}$ for an extended period of time (longer than 2 h) (Fig. 1).

NMR spectroscopy was subsequently applied to monitor $\mathrm{Ni}^{2+}$ binding to $H p S l y D$ as well as potential metal-induced structural changes. The $2 \mathrm{D}\left[{ }^{1} \mathrm{H}-{ }^{15} \mathrm{~N}\right] \mathrm{HSQC}$ spectrum of the full-length $H p$ SlyD was assigned on the basis of that of $H p$ SlyD $\Delta$ C. Addition of $\mathrm{Ni}^{2+}$ at a molar ratio of $\mathrm{Ni}^{2+}$ to protein of 0.6:1 led to several cross-peaks decreasing in intensity and new peaks appearing. The latter are assigned as the bound forms. The observation of two sets of peaks indicated that the apo and $\mathrm{Ni}^{2+}$-bound forms are in slow exchange on the NMR timescale. On further addition of $\mathrm{Ni}^{2+}$ to a molar ratio of $\mathrm{Ni}^{2+}$ to protein of 1:1, the cross-peaks for the apo form disappeared completely, whereas those of the bound form further increased in intensity. No apparent changes were observed upon further titration of $\mathrm{Ni}^{2+}$ to a ratio of $2: 1 \mathrm{Ni}^{2+}$ to protein. The chemical shift perturbation upon $\mathrm{Ni}^{2+}$ binding was quantified and changes larger than $0.03 \mathrm{ppm}$ were noticed for Glu-18, Asp-29, Ile-46, Ile-47, Gly-49, Lys-52, Val-65, and Arg-138. Significantly, these residues can be mapped exclusively into the PPIase domain of the protein (Fig. 5a) and are either very close to or belong to the active sites. Some residues likely from $\alpha 4$ are also perturbed upon $\mathrm{Ni}^{2+}$ binding, suggesting the importance of this helix. As a control, ${ }^{15} \mathrm{~N}$-labeled $H p \operatorname{SlyD} \Delta \mathrm{C}$ was also titrated with $\mathrm{Ni}^{2+}$ (up to 2 molar equiv), resulting in no significant chemical shift perturbation, indicating that $\mathrm{Ni}^{2+}$ itself neither binds to $H p \operatorname{SlyD} \Delta \mathrm{C}$ nor changes its chemical environment. Surprisingly, addition of $\mathrm{Zn}^{2+}$ to the protein caused no chemical shift perturbation in the PPIase domain (data not shown), clearly indicating the difference in either coordinating ligands or geometry between these two metal ions. $\mathrm{Ni}^{2+}$-induced structural changes were also noted previously for EcSlyD [10], and recent crystal structures of both apo-TtSlyD and $\mathrm{Ni}^{2+}$-bound TtSlyD [8] further illustrate such metal-induced structural changes, which might be potentially important in the accomplishment of their biological functions.

IF domain is responsible for binding to Tat signal peptide of HydA from H. pylori

It has been suggested previously that SlyD binds different Tat signal peptides in E. coli such as DnaK as a general chaperone for Tat signal-binding protein [19]. HpSlyD has also been implicated to serve an important role in ensuring the transport of holohydrogenase across the inner membrane into the periplasm by interacting with Tat signal peptide of HydA (small subunit of hydrogenase) of H. pylori [6]. However, there appears lack of direct evidence for such an interaction. Therefore, we constructed HydA Tat signal-fused protein to examine its interaction with the protein by NMR spectroscopy. The sequence of the Tat signal peptide (1-69 amino acids) from pre-HydA of of $H$. pylori (HP0631) with a longer n-region (positively charged amino-terminal region), which is much longer than normal Tat signal peptides (normally 38 amino acids) [47], was predicted using ScanProsite (http://expasy.org/tools/ scanprosite/) with a score of 8.433 . The Tat signal peptide was fused to the C-terminus of the signal-peptide-less MBP. Since the Tat signal peptide is located between the MBP and a C-terminal hexahistidine tag, only full-length, signal-peptidase-uncleaved chimera $\Phi$ MalE::HydASP-H6 can be purified by IMAC. The MBP-tagged Tat peptide was added at approximately 1:1 ratio to a solution of ${ }^{15} \mathrm{~N}$ labeled $H p S l y D \Delta C$. The residues experiencing large chemical shift perturbations (larger than $0.06 \mathrm{ppm}$ ) consisted of Asn-31, Ile-41, Gly-42, Ile-46, Leu-81, Val-84, Gly-102, Thr-104, Glu-105, Asp-106, Thr-109, Ile-110, Gln-111, Ala-112, and Asp-125. Most of these residues localized in the IF domain (Fig. 5b). Surprisingly, several residues (Ile-41, Gly-42, Ile-46, and Asn-31) were from the FKBP domain, which is likely due to the binding of the longer n-region of HydA Tat peptide to the FKBP domain. The MBP tag alone showed no interaction with $H p \operatorname{SlyD} \Delta \mathrm{C}$ on the basis of an NMR experiment (data not shown).

\section{PPIase active sites and activity of $H p$ SlyD}

The substrate binding sites are located at the highly conserved PPIase domain of FKBP and FKBP-like proteins. Since the active sites are highly conserved among different members of the family proteins, the corresponding binding pocket in $H p S l y D$ was identified on the basis of structural alignments (Fig. 6), which consists of residues Tyr-17, Leu-28, Asp-29, Leu-37, Phe-39, Ile-46, Ile-47, Leu-50, Tyr-73, Leu-135, and Phe-137. Ile-90 and Ile-91 of HsFKBP12 are unique and there are no corresponding residues in other homologues. Comparing the active sites of FKBPs from three species (Fig. 6), we demonstrated that the active site of $H p S l y D \Delta C$ is slightly different from that of both HsFKBP12 and EcSlyD. Specifically, Phe-39, Leu37, and Leu-135 are situated at positions which could not be superimposed with their counterparts and the substrate binding pocket for $H p S l y D \Delta C$ is much larger than that of HsFKBP12 and EcSlyD (Fig. 6).

The PPIase activities $\left(k_{\mathrm{cat}} / K_{\mathrm{m}}\right)$ obtained from the singleproline-limited RCM-T1 refolding are summarized in Fig. 

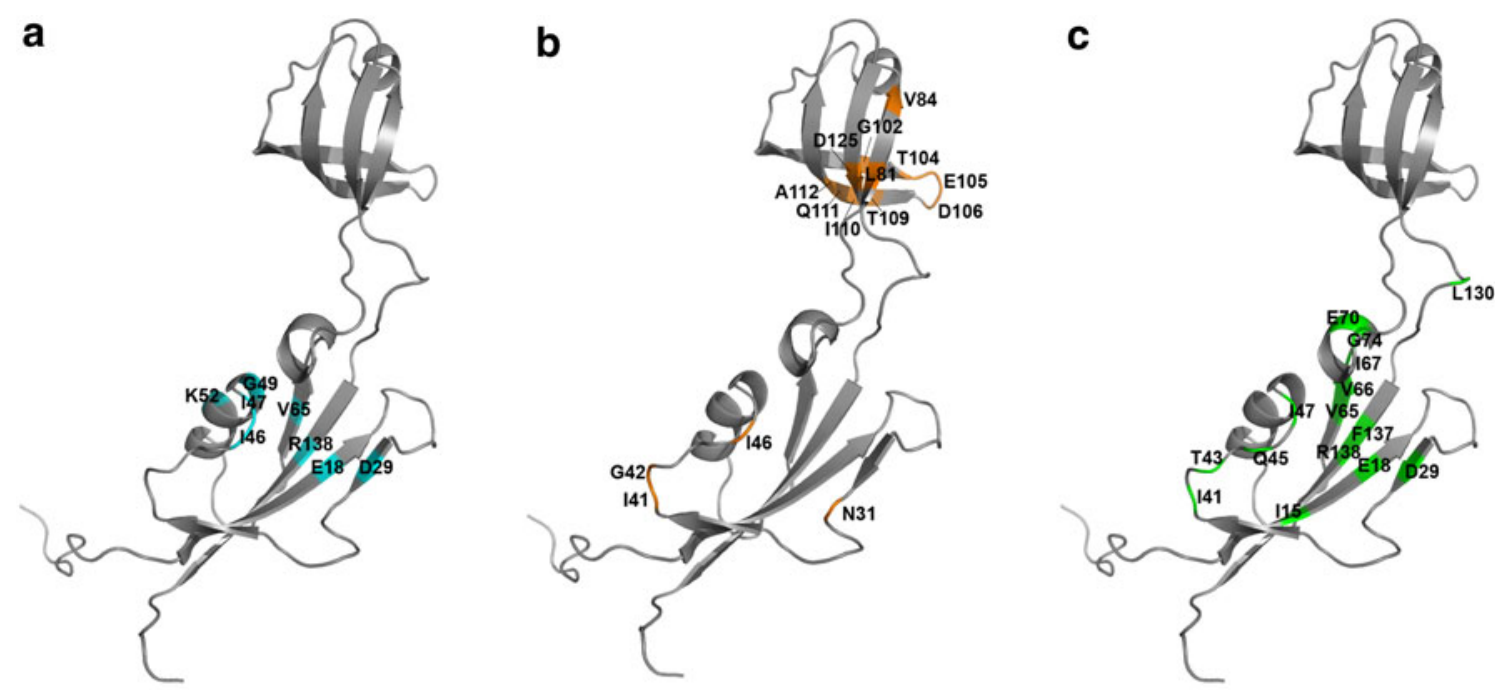

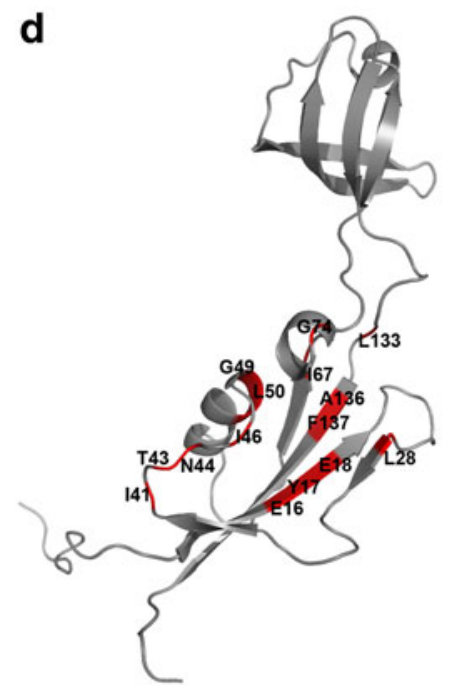

Fig. 5 Structural mapping of the residues experiencing relatively large chemical shift perturbations upon interactions of the protein with $\mathbf{a ~} \mathrm{Ni}^{2+}, \mathbf{b}$ twin-arginine translocation (Tat) signal peptide of HydA from $H$. pylori, c FK506, d rapamycin, e reduced and

S5 and Table S2. The PPIase activity of HpSlyD $\left(1.17 \times 10^{6} \mathrm{M}^{-1} \mathrm{~s}^{-1}\right)$ is comparable to that of EcSlyD $\left(0.82 \times 10^{6} \mathrm{M}^{-1} \mathrm{~s}^{-1}\right.$ at $\left.15^{\circ} \mathrm{C}\right)$ [29] or TtSlyD $(0.29 \times$ $10^{6} \mathrm{M}^{-1} \mathrm{~s}^{-1}$ at $15{ }^{\circ} \mathrm{C}$ ) [8], considering that our refolding assay was conducted at $20^{\circ} \mathrm{C}$. Deletion of the C-terminus only slightly reduced (approximately 20\%) the PPIase activity. In contrast, the activities decreased by approximately 400- and 1,000-fold, respectively, for the loss of the IF domain $(H p S l y D \Delta I F)$ and the loss of both the IF domain and the $\mathrm{C}$-terminus ( $H p \operatorname{SlyD} \Delta \mathrm{IF} \Delta \mathrm{C})$. These results suggest that the metal-binding $\mathrm{C}$-terminus has subtle effects on the catalytic activity of the protein and chaperone-active IF domain is likely to facilitate the functioning of the FKBP carboxymethylated $\alpha$-lactalbumin, and $\mathbf{f}$ insulin. All experiments were conducted using $\mathrm{HpSlyD} \Delta \mathrm{C}$, except for $\mathrm{Ni}^{2+}$ titration, in which fulllength $H p S l y D$ was used

domain in proline-dependent refolding of protein substrates.

Previously, both FK506 and rapamycin have been shown to act as potent inhibitors of the PPIase activity of some of the FKBPs (e.g., HsFKBP12 [42] and MtFKBP17 [11]). The chemical shift perturbations induced by either direct binding or conformational changes were evaluated. Addition of FK506 caused shifts of several residues, e.g., Ile-15, Glu-18, Asp-29, Ile-41, Thr-43, Gln-45, Ile-47, Val65, Val-66, Ile-67, Glu-70, Gly-74, Leu-130, Phe-137, and Arg-138. These residues are exclusively from the FKBP domain and are located either on or near the active sites (Fig. 5c), indicating a chemical shift variation on the fast 
equilibrium timescale. Similar results were obtained for rapamycin (Fig. 5d), except that perturbed residues experience chemical shift variation on the slow equilibrium timescale. These results demonstrated that both immunosuppressive agents are able to compete with the substrate for binding to the active sites, resulting in the inhibition of the PPIase activity of $H p S l y D$. In both cases, the residues for the IF domain remained unperturbed. As shown in Table S2, the drugs inhibit the PPIase activity only at a relatively high concentration $(10 \mu \mathrm{M})$, probably attributed to the low affinity of the drugs for the active sites $[9,48]$.

\section{Chaperone activity of the IF domain}

The IF domain of HpSlyD is highly flexible and has large exposed hydrophobic surfaces, which results in its binding to unfolded hydrophobic protein or peptide patches. Such a chaperone activity of the protein was noticed previously in other FKBP family proteins [8-11]. To gain deep insight into the chaperone activity of $H p S l y D$, several unfolded proteins or peptides were used to interact with the protein (unlabeled or ${ }^{15} \mathrm{~N}$-labeled $H p \operatorname{SlyD} \Delta \mathrm{C}$ ) monitored by either fluorescence spectroscopy or $2 \mathrm{D}\left[{ }^{1} \mathrm{H}-{ }^{15} \mathrm{~N}\right]$ HSQC.

As expected, when well-folded proteins were added to $0.3 \mathrm{mM}{ }^{15} \mathrm{~N}$-labeled $H p \operatorname{SlyD} \Delta \mathrm{C}$, no chemical shift perturbation was observed, indicating there was no interaction (data not shown). In contrast, when RCM-La, a permanently unfolded model substrate, was added to the protein solution, large chemical shift changes (larger than $0.04 \mathrm{ppm}$ ) were found for Leu-81, Phe-89, Ile-92, Glu-93, Val-100, Asp-106, Ile-110, and Ala-112 (Fig. 5e). In addition, Gly-102 completely disappeared. These residues are exclusively located at the IF domain (Fig. 5e). Similarly, the aggregation-prone insulin $\mathrm{B}$ chain binds to $H p S l y D \Delta C$ and perturbed chemical shifts (larger than $0.04 \mathrm{ppm}$ ) of residues exclusively from the IF domain, e.g., Leu-81, Val-84, Phe-89, Val-100, Gly-102, Gln-103, Asp106, Asn-107, Thr-109, Ile-110, Gln-111, His-128, and Leu-130 (Fig. 5f).

The chaperone activities were investigated for $H p S l y D$ and its variants as shown in Fig. S6. At a molar ratio of proteins to insulin of about $0.5: 1, H p$ SlyD reduced the intensity of the scattered light by almost a half owing to the aggregation of insulin, whereas $H p \operatorname{SlyD} \Delta \mathrm{C}$ caused less reduction in the intensity of the scattered light. Further increase in the molar ratio of proteins to insulin to $1: 1$ resulted in complete inhibition of DTT-induced aggregation of insulin $\mathrm{B}$ for both $H p S l y \mathrm{D}$ and $H p \operatorname{SlyD} \Delta \mathrm{C}$, indicating that the $\mathrm{C}$-terminus is not indispensable for chaperone function of the IF domain. However, $H p S l y D \Delta \mathrm{IF}$ and $H p S l y D \Delta \mathrm{IF} \Delta \mathrm{C}$, lacking the IF domain, exhibited almost no chaperone activity.

\section{Discussion}

Unique structural properties of SlyD

The solution structure of $H p \operatorname{SlyD} \Delta \mathrm{C}$ reported here is similar to that of homologues such as EcSlyD $[9,10]$, TtSlyD [8], and MtFKBP17 [11] with two functional, spatially separated and orientation-independent domains, the FKBP and IF domains. The additional C-terminal $\alpha 4$ in the FKBP domain is likely present in full-length $H p$ SlyD (Fig. 7), and is also found in EcSlyD [9, 10] and TtSlyD [8], and might be a common feature for SlyD proteins. $\alpha 4$ represents a novel extension to the PPIase fold and is probably coupled with the C-terminal metal-binding tail to regulate PPIase activity, which is manifested by conformational changes of the protein upon binding of $\mathrm{Ni}^{2+}$ (Fig. 5a), in agreement with the findings of a previous study on EcSlyD [10]. Similar to other SlyD-like FKBPs, the two domains of $H p$ SlyD are self-oriented and lack interdomain contacts, and exhibit different rotational correlation times. Such an orientational arrangement of the two domains may facilitate mutual cooperation for protein functioning, which may be a common characteristic for SlyD proteins, distinct from other PPIases containing additional chaperone domains, e.g., trigger factor [49], periplasmic FkpA [50], and SurA [51]. The PPIase and chaperone activities of these proteins are normally independent owing to lack of internal mobility. The catalytic sites of SlyD proteins are highly conserved and consist of mainly hydrophobic residues to enable substrate binding (Figs. 6, 7). Differences in the properties of certain residues such as deeper penetration of Tyr-68 in EcSlyD [9] or the size of the hydrophobic pocket (smaller in TtSlyD [8] but larger in $H p$ SlyD) may result in slight differences in the catalytic activity. In particular, the IF domain has an "incomplete" $\beta$-barrel structure with high conformational dynamics (Fig. S4), allowing it to adapt rapidly to different unfolded protein substrates. Binding of unfolded protein substrates would significantly increase the stability of this domain by the "completion" of the $\beta$-barrel [8]. Taken together, the unique structure properties of SlyD may provide a basis for multifunctionality of the protein.

\section{Metal binding properties}

Different from EcSlyD [10, 17], no significant changes in the circular dichroism spectra of $H p$ SlyD were observed upon addition of different metal ions, indicative of identical secondary structure of the protein. For EcSlyD, the binding of $\mathrm{Ni}^{2+}$ causes the conversion of about $10 \%$ of $\beta$ sheet structure into an irregular structure [10]. This may account for the different length and composition of the $\mathrm{C}$-terminal tail, since the C-terminus of $\mathrm{HpSlyD}$ possesses 


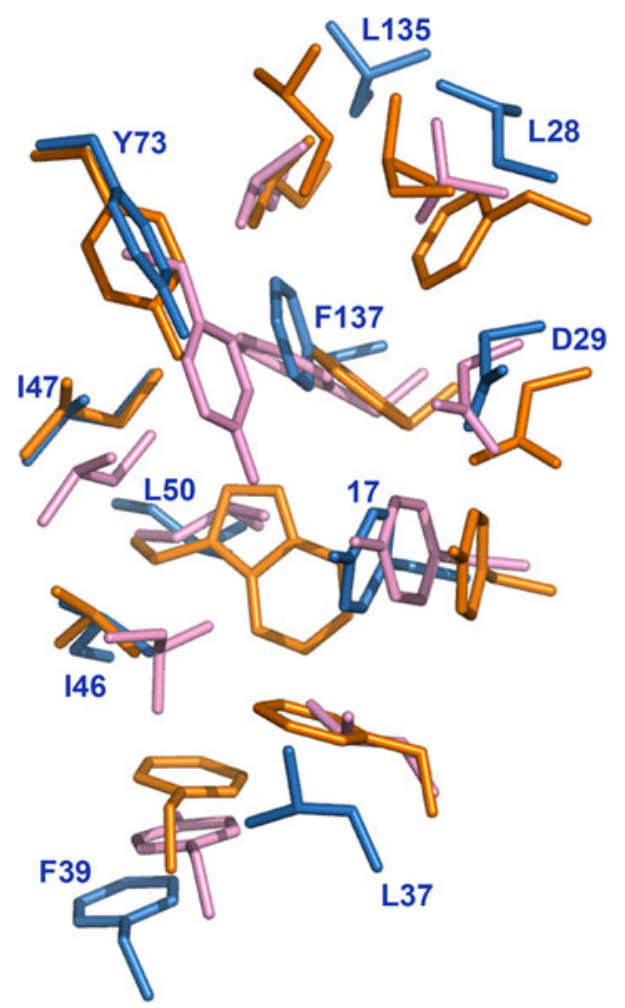

Fig. 6 Superimposition of the side chains of the residues in catalytic sites of three FKBP homologues: HpSlyD $\Delta \mathrm{C}$ (sky blue), HsFKBP12 (orange), and EcSlyD (pink). The numbering of the residues corresponds to $H p S l y D \Delta C$

no negatively charged residues (Glu and Asp), unlike in EcSlyD. Furthermore, on the basis of sequence alignment, $H p$ SlyD lacks the conserved HGHXH sequence motif at the beginning of the C-terminus, which was shown to tightly bind $\mathrm{Ni}^{2+}$ [8] and is shared by other non-epsilonproteobacterial SlyD homologues (Fig. 7). Our 2D $\left[{ }^{1} \mathrm{H}-{ }^{15} \mathrm{~N}\right] \mathrm{HSQC}$ data demonstrated that binding of $\mathrm{Ni}^{2+}$ (only the first stoichiometry) to the protein perturbed several residues in the active sites of the PPIase domain, suggesting that residues in this region either directly interact with metal ions or undergo certain conformational changes. In contrast, no such perturbation was observed upon $\mathrm{Zn}^{2+}$ binding, probably owing to the binding of metal at the C-terminus, which is too flexible to be observed in the $2 \mathrm{D}\left[{ }^{1} \mathrm{H}_{-}{ }^{15} \mathrm{~N}\right]$ HSQC spectrum. No histidines are involved in nickel binding except at the $\mathrm{C}$-terminus, again different from EcSlyD (His-36 and His-38 bind nickel ions) [10]. Unlike EcSlyD (most residues at $\beta 5$ b), two important residues for catalysis (Leu-37 and Phe-39 of $\mathrm{HpSlyD}$ ) were not affected upon nickel binding owing to the absence of histidine residues. We hypothesized that the effect of nickel binding on PPIase activity of $H p S l y D$ is different from that for EcSlyD, possibly owing to the $\beta$-sheet $\beta 5 \mathrm{~b}$ being undisrupted upon binding. The inhibition of the PPIase activity upon nickel binding [17] is mainly due to the unnecessity of the activity during the maturation processes of [NiFe] hydrogenase [52].

Interestingly, zinc ions induce the dimerization of the protein but not nickel, as shown in Fig. 1. The loss of zinc from $\mathrm{HpSlyD}$ may favor the normal function of SlyD.

Implication of $H p S l y D$ in maturation of urease and hydrogenase

Both [NiFe] hydrogenase and urease are crucial for H. pylori and their maturations are complicated, involving multiple chaperones and maturation factors [1]. SlyD has been shown to participate in the maturation of both urease and hydrogenase in $H$. pylori $[6,15]$. A recent interactomics study in $H$. pylori showed that SlyD interacts with HypB (a nickel-binding accessory protein) [6]. Such an interaction was also observed in E. coli [13], and the deletion of the IF domain of SlyD or the mutation of the proline-rich stretch between the N-terminal CXXCGC nickel-binding motif and the GTPase domain of НypB disrupted the interaction [53]. HypB from $H$. pylori (HpHypB; UniProt accession number O25560) lacks both the N-terminal nickel binding site and the proline-rich region. Nevertheless, our preliminary work indicated that HpSlyD binds to HpHypB (data not shown). The molecular and structural basis for such an interaction might be distinct from that for $E$. coli and is currently under investigation in our laboratory.

We demonstrated that HpSlyD binds the Tat signal peptide of the H. pylori [NiFe] hydrogenase small subunit for the first time (Fig. 5b). In E. coli, two chaperone proteins, HyaE and HybE, were shown to be able to interact with Tat-signal-peptide-bearing hydrogenase ([NiFe] hydrogenases 1 and 2) precursors to proofread the assembly of hydrogenase complexes and prevent the export of immature Tat-dependent hydrogenases [54]. However, there is no homologue of the two proteins in H. pylori; SlyD may therefore serve a similar role to $\mathrm{HyaE}$ and HybE and participate in the maturation process of hydrogenase in H. pylori by binding to Tat signal peptide of [NiFe] hydrogenase and escorting it to the Tat translocon as proposed previously [6]. It remains unclear how SlyD senses the immature [NiFe] hydrogenase and ensures insertion of the cofactor and transports the maturated hydrogenase complex across the cytoplasmic membrane. Further study is necessary to clarify whether the unique C-terminus of SlyD plays such a role. The physiological relevance of the nickel binding and the associated conformational changes of SlyD in $H$. pylori remain to be defined.

Sequence comparison of НрНурВ with its counterparts in other species showed that HpHypB is deficient in nickel binding residues such as a polyhistidine stretch, which 


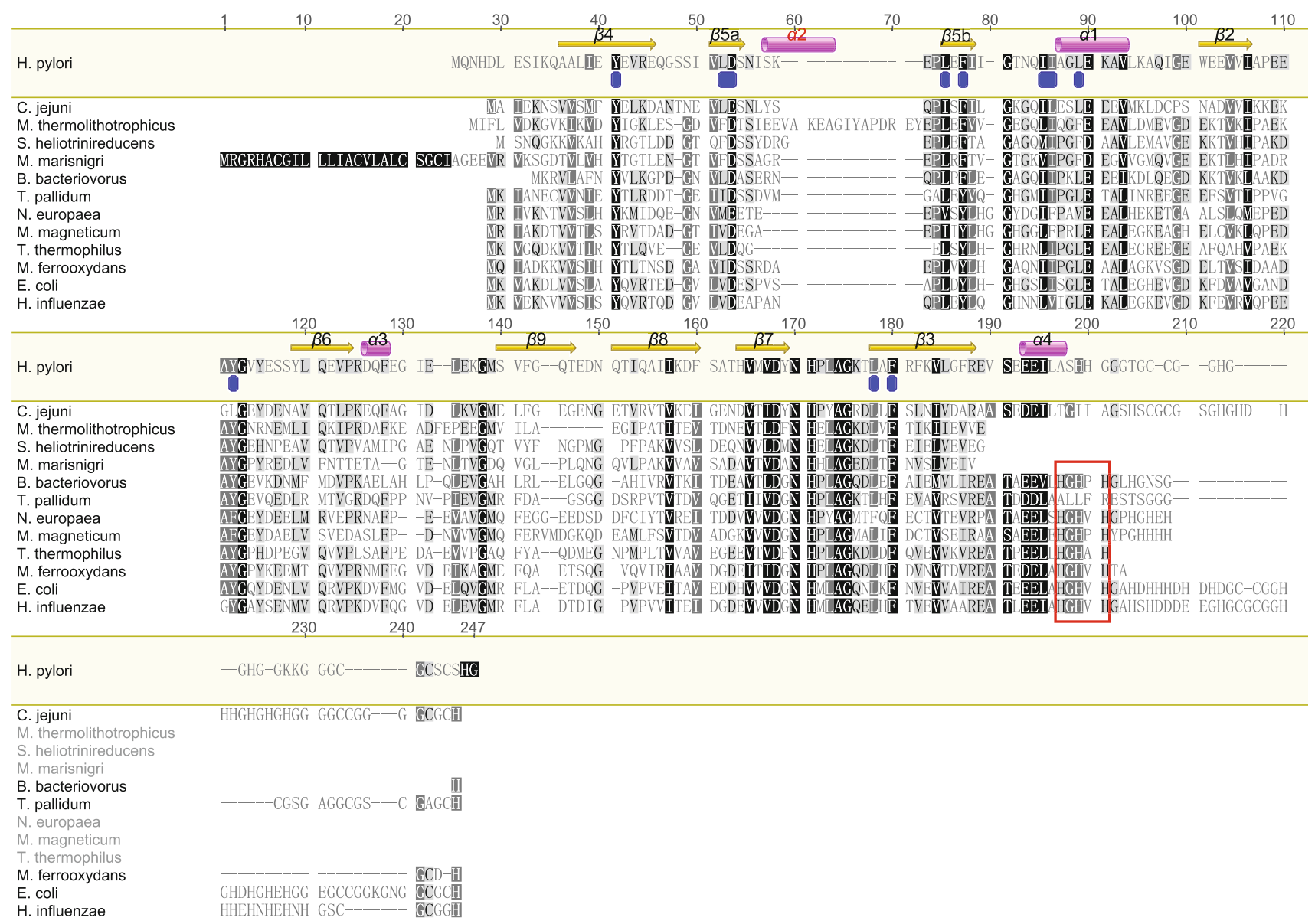

Fig. 7 Multiple sequence alignments of $H p$ SlyD and its homologues using the MUSCLE algorithm [56] with default parameters. Secondary structure elements were annotated by Geneious 5.3.4 (http://www.geneious.com) according to the calculated NMR structure as shown in Fig. 2c and other resolved structures of SlyD homologues. The $\alpha 2$ helix (in red) is only present in FKBP from Methanothermococcus thermolithotrophicus (MtFKBP17). Identical and similar residues between the homologues are highlighted in black or gray. The conserved HGHXH sequence previously mentioned is encircled in a red box. Residues of peptidylprolyl isomerase (PPIase)

might be compensated by the C-terminal extended $H p$ SlyD. The binding of nickel ions to SlyD impaired the PPIase activity of SlyD [17], which is not required for hydrogenase assembly in E. coli as demonstrated previously [53], through conformational changes. We propose that SlyD, once bound to nickel ions, will donate the metal ions by working together with $\mathrm{HypA} / \mathrm{HypB}$ in urease maturation [15]. Prior to insertion of nickel ions into hydrogenase, HpSlyD will prohibit the transport of the immature, cofactor-deficient $[\mathrm{NiFe}]$ hydrogenase across the cytoplasmic membrane by binding to the hydrogenase small subunit Tat signal peptide. Recently, SlyD in E. coli was shown to have the capability to interact with the Tatsignal-peptide-free large-subunit $[\mathrm{NiFe}]$ hydrogenase 3 catalytic sites of $H p$ SlyD are highlighted with blue. The UniPort accession numbers are as follows: Q6MQW6 (Bdellovibrio bacteriovorus SlyD), A1VXJ8 (Campylobacter jejuni SlyD), P0A9K9 (EcSlyD), P44830 (Haemophilus influenza SlyD), O25748 (HpSlyD), Q0EWE3 (Mariprofundus ferrooxydans), Q2W0E9 (Magnetospirillum magneticum), A3CV43 (Methanoculleus marisnigri FKBP PPIase), O52980 (MtFKBP17), Q82U07 (Nitrosomonas europaea SlyD), C7N8E0 (Slackia heliotrinireducens PPIase), O83369 (Treponema pallidum SlyD), and Q5SLE7 (TtSlyD)

(HycE) through its IF domain [55], which complicated the role of SlyD in the maturation process of hydrogenase. The present study might at least shed light on the role of SlyD in the hydrogenase assembly and translocation.

Acknowledgments This work was supported by the Research Grants Council of Hong Kong (HKU107C, HKU704207P, HKU703808P, HKU704909P, N_HKU75209), the Croucher Foundation, and the University of Hong Kong. Electrospray ionization mass spectrometry was performed at the High Performance Tandem Mass Spectrometry Facility (HKU), partially supported by a Special Equipment Grant from the University Grants Committee of the Hong Kong Special Administrative Region, China (project code SEG_HKU02). The coordinates and chemical shifts of HpSlyD have been deposited in the Protein Data Bank (2KR7) and BioMagResBank (16629). 
Open Access This article is distributed under the terms of the Creative Commons Attribution Noncommercial License which permits any noncommercial use, distribution, and reproduction in any medium, provided the original author(s) and source are credited.

\section{References}

1. Kusters JG, van Vliet AHM, Kuipers EJ (2006) Clin Microbiol Rev 19:449-490

2. Evans DJ Jr, Evans DG, Kirkpatrick SS, Graham DY (1991) Microb Pathog 10:15-26

3. Maier RJ, Fu C, Gilbert J, Moshiri F, Olson J, Plaut AG (1996) FEMS Microbiol Lett 141:71-76

4. Benoit S, Maier RJ (2003) J Bacteriol 185:4787-4795

5. Mehta N, Olson JW, Maier RJ (2003) J Bacteriol 185:726-734

6. Stingl K, Schauer K, Ecobichon C, Labigne A, Lenormand P, Rousselle JC, Namane A, de Reuse H (2008) Mol Cell Proteomics 7:2429-2441

7. Olson JW, Mehta NS, Maier RJ (2001) Mol Microbiol 39:176-182

8. Löw C, Neumann P, Tidow H, Weininger U, Haupt C, FriedrichEpler B, Scholz C, Stubbs MT, Balbach J (2010) J Mol Biol 398:375-390

9. Weininger U, Haupt C, Schweimer K, Graubner W, Kovermann M, Brüser T, Scholz C, Schaarschmidt P, Zoldak G, Schmid FX, Balbach J (2009) J Mol Biol 387:295-305

10. Martino L, He Y, Hands-Taylor KL, Valentine ER, Kelly G, Giancola C, Conte MR (2009) FEBS J 276:4529-4544

11. Suzuki R, Nagata K, Yumoto F, Kawakami M, Nemoto N, Furutani M, Adachi K, Maruyama T, Tanokura M (2003) J Mol Biol 328:1149-1160

12. Kay JE (1996) Biochem J 314:361-385

13. Zhang JW, Butland G, Greenblatt JF, Emili A, Zamble DB (2005) J Biol Chem 280:4360-4366

14. Roof WD, Fang HQ, Young KD, Sun JL, Young R (1997) Mol Microbiol 25:1031-1046

15. Benanti EL, Chivers PT (2009) J Bacteriol 191:2405-2408

16. Wülfing C, Lombardero J, Plückthun A (1994) J Biol Chem 269:2895-2901

17. Hottenrott S, Schumann T, Plückthun A, Fischer G, Rahfeld JU (1997) J Biol Chem 272:15697-15701

18. Mitterauer T, Nanoff C, Ahorn H, Freissmuth M, Hohenegger M (1999) Biochem J 342:33-39

19. Graubner W, Schierhorn A, Brüser T (2007) J Biol Chem 282:7116-7124

20. Ilver D, Rappuoli R, Telford JL (2001) In: Mobley HLT, Mendz GL, Hazell SL (eds) Helicobacter pylori: physiology and genetics. ASM Press, Washington, pp 219-226

21. Dalbey RE, Robinson C (1999) Trends Biochem Sci 24:17-22

22. Wickner W, Schekman R (2005) Science 310:1452-1456

23. Ge RG, Zhang Y, Sun XS, Watt RM, He QY, Huang JD, Wilcox DE, Sun HZ (2006) J Am Chem Soc 128:11330-11331

24. Ge RG, Watt RM, Sun XS, Tanner JA, He QY, Huang JD, Sun HZ (2006) Biochem J 393:285-293

25. Ge RG, Sun HZ (2007) Acc Chem Res 40:267-274
26. Zeng YB, Zhang DM, Li HY, Sun HZ (2008) J Biol Inorg Chem 13:1121-1131

27. Cun SJ, Li HY, Ge RG, Lin MCM, Sun HZ (2008) J Biol Chem 283:15142-15151

28. Xia W, Li H, Sze KH, Sun HZ (2009) J Am Chem Soc 131:10031-10040

29. Knappe TA, Eckert B, Schaarschmidt P, Scholz C, Schmid FX (2007) J Mol Biol 368:1458-1468

30. Maillard J, Spronk CAEM, Buchanan G, Lyall V, Richardson DJ, Palmer T, Vuister GW, Sargent F (2007) Proc Natl Acad Sci USA 104:15641-15646

31. Gill SC, von Hippel PH (1989) Anal Biochem 182:319-326

32. Delaglio F, Grzesiek S, Vuister GW, Zhu G, Pfeifer J, Bax A (1995) J Biomol NMR 6:277-293

33. Goddard TD, Kneller DG. SPARKY 3. University of California, San Francisco

34. Cornilescu G, Delaglio F, Bax A (1999) J Biomol NMR 13:289-302

35. Grzesiek S, Bax A, Clore GM, Gronenborn AM, Hu JS, Kaufman J, Palmer I, Stahl SJ, Wingfield PT (1996) Nat Struct Biol 3:340-345

36. Herrmann T, Güntert P, Wüthrich K (2002) J Mol Biol 319:209-227

37. Pearlman DA, Case DA, Caldwell JW, Ross WS, Cheatham TE, Debolt S, Ferguson D, Seibel G, Kollman P (1995) Comput Phys Commun 91:1-41

38. Laskowski RA, Rullmann JAC, MacArthur MW, Kaptein R, Thornton JM (1996) J Biomol NMR 8:477-486

39. Koradi R, Billeter M, Wüthrich K (1996) J Mol Graph 14:51-55

40. DeLano WL (2006) PyMOL, release 0.99rc6. DeLano Scientific, Palo Alto

41. Scholz C, Eckert B, Hagn F, Schaarschmidt P, Balbach J, Schmid FX (2006) Biochemistry 45:20-33

42. Van Duyne GD, Standaert RF, Karplus PA, Schreiber SL, Clardy J (1991) Science 252:839-842

43. Holm L, Park J (2000) Bioinformatics 16:566-567

44. Stibrany RT, Fox S, Bharadwaj PK, Schugar HJ, Potenza JA (2005) Inorg Chem 44:8234-8242

45. Lever ABP (1984) Inorganic electronic spectroscopy, 2nd edn. Elsevier, Amsterdam

46. Chivers PT, Sauer RT (2000) J Biol Chem 275:19735-19741

47. Cristóbal S, de Gier JW, Nielsen H, von Heijne G (1999) EMBO J 18:2982-2990

48. Zoldák G, Schmid FX (2011) J Mol Biol 406:176-194

49. Ludlam AV, Moore BA, Xu ZH (2004) Proc Natl Acad Sci USA 101:13436-13441

50. Saul FA, Arié JP, Vulliez-le Normand B, Kahn R, Betton JM, Bentley GA (2004) J Mol Biol 335:595-608

51. Bitto E, McKay DB (2002) Structure 10:1489-1498

52. Zhang JW, Leach MR, Zamble DB (2007) J Bacteriol 189:7942-7944

53. Leach MR, Zhang JW, Zamble DB (2007) J Biol Chem 282:16177-16186

54. Dubini A, Sargent F (2003) FEBS Lett 549:141-146

55. Chung KCC, Zamble DB (2011) FEBS Lett 585:291-294

56. Edgar RC (2004) Nucleic Acids Res 32:1792-1797 